\section{RECRUITMENT OPENS FOR NICE FELLOWS AND SCHOLARS}

Recruitment for the 2015 intake of NICE Fellows and Scholars opens this autumn. The programme recognises the achievement and promise of health, public health and social care professionals who are working to improve the quality of care.

The National Institute for Health and Care Excellence (NICE) aims to recruit ten Fellows and ten Scholars each year. Fellows and Scholars benefit from professional development opportunities and get to meet and work with likeminded colleagues from different disciplines across the UK. The programme fosters a growing network of professionals linked to NICE who are united by the common goal of ensuring that high quality, cost effective care is commissioned and provided across the health and social care system.

NICE Fellows are senior health and social care leaders who are ambassadors for the Institute at regional and national levels and among their professional groups and peers. Over the course of their three-year fellowship they are expected to build a network of influential professionals who will support NICE in the implementation of its guidance, driving up the quality of care delivered and encouraging the adoption of cost effective innovation into practice.

NICE Scholarships are oneyear opportunities for qualified health and social care professionals to find out about the inner workings of NICE and undertake a supported improvement project, related to NICE guidance, within their local organisation. NICE Scholars are expected to act as local ambassadors for clinical and public health and social care excellence and promote the principles and the recommendations of NICE guidance.

For further information visit www.nice.org.uk or email liz.robb@btopenworld.com.

\section{LEARNING THROUGH PLAY PROJECT A SUCCESS}

The charity Action for Sick Children, based in Stockport, has reported great success with their Dental Playbox Project, with a 49\% increase in the number of children seen at sessions in 2012.

The Dental Playbox Project aims to teach children, through play, about the importance of healthy eating and prepare them from an early age for a trip to the dentist. Through play children can learn and express any fears that they may have in a safe and secure environment.

In 2011 facilitators visited 133 locations and 3,769 children; in 2012, 203 locations and 7,240 children; in 2013258 locations and 6,343 children.

A specially designed box of resources including role play uniforms, hand puppets, games, stories, toothbrushes and a teacher's pack is left for a week after a session for the children to continue learning.

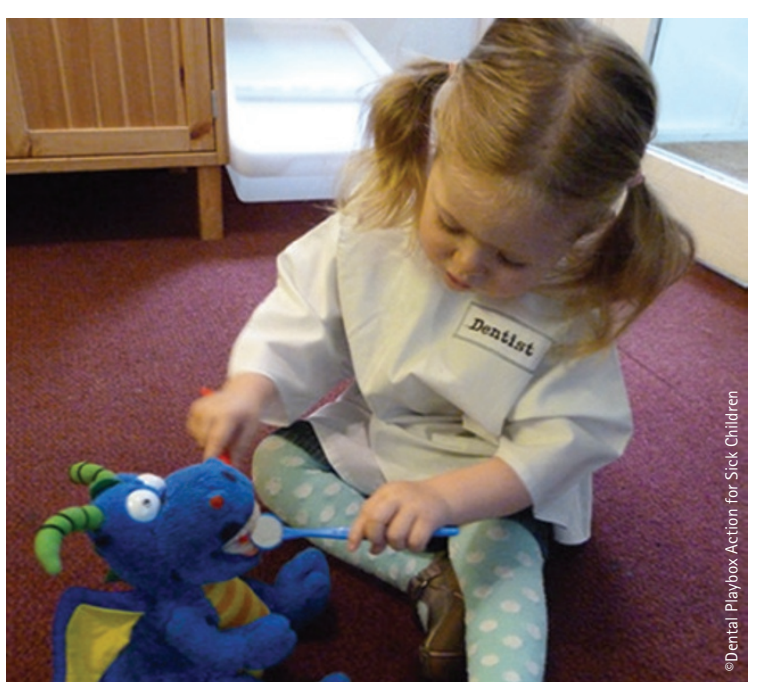

Manager of the Dental Playbox Project, Teresa Dooley, said: 'The number of children with dental problems is growing at an alarming rate, putting an even greater strain on the healthcare industry. Dental Playbox is a fun way for children to learn about the importance of visiting the dentist and looking after their teeth'.

\section{BOOK REVIEW}

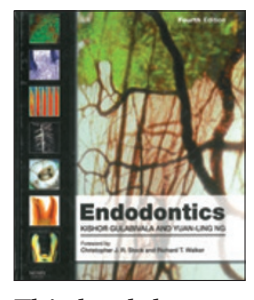

\section{ENDODONTICS, 4TH EDITION \\ K. Gulabivala, Y. Ng \\ Elsevier \\ price £113.00; pp 398 \\ ISBN 9780702031557}

This book has 17 chapters in four sections: rationale for disease management, preparation for delivery of endodontic treatment, delivery of endodontic treatment, and multidisciplinary aspects of endodontic management. Chapters begin with a helpful synopsis outlining aims and application of the content and are divided into smaller sub-sections with summarising tables and graphs to highlight important points. Chapters are also supported by referenced scientific articles for further reading.

Aimed at general dental practitioners and dentists with an interest in endodontics, this text provides an excellent step-by-step guide through clinical topics including assessment and diagnosis of endodontic problems, a helpful chapter on treatment planning and a comprehensive section on delivery of endodontic treatment, including management of treatment failure. Other sections include management of acute emergencies and traumatic dental injuries and management of tooth resorption. Discussion of endodontic procedures and guidance on treatment modalities are presented in an easy-to-follow manner, accompanied by more than 1,500 helpful illustrations, alongside colour clinical photographs and radiographs. Endodontics also covers multidisciplinary management, which is essential to consider when diagnosing dental disease. Chapters include discussion of the interface with periodontics, restorative dentistry, orthodontics, oral surgery, oral medicine and orofacial pain.

The strength of this text is providing a systematic, problemsolving approach to managing endodontic treatment, combining relevant best practice evidence with comprehensive explanations of current treatment methods and applicable clinical advice. A personal highlight was the discussion of management and avoidance of common endodontic pitfalls. This is a fairly extensive text and will require investing time to gain most value. However, I feel the wellorganised layout also gives it merit as a reference for readers who wish to consult a specific aspect of endodontic management or clinical quick reference guide, or to browse periodically over lunch breaks.

Endodontics is a valuable resource for clinicians at all levels with an interest in this specialty and also for those looking for practical advice to improve their clinical practice.

P. FEE 